\title{
Measurement of Noise Reduction from Acoustic Casing Treatments Installed Over a Subscale High Bypass Ratio Turbofan Rotor
}

\author{
Richard F. Bozak* \\ NASA Glenn Research Center, Cleveland, Ohio, 44135, USA \\ Robert P. Dougherty ${ }^{\dagger}$ \\ OptiNav Inc., Bellevue, Washington, 98005, USA
}

\begin{abstract}
NASA is continuing to develop over-the-rotor acoustic liners for turbofan applications. A series of low Technology Readiness Level experiments were conducted to better understand the acoustic and aerodynamic effects of these acoustic liners. The final experiment included the evaluation of four acoustic casing treatment concepts and two baseline configurations in an internal flow axial compressor facility with a 1.5 pressure-ratio high-bypass turbofan rotor. An inlet in-duct array was utilized to extract sound power levels propagating forward from the turbofan rotor. The effect of a circumferentially grooved relative to a hardwall fan case was found to reduce the in-duct sound power level by about $1.5 \mathrm{~dB}$ for frequencies less than $2 \mathrm{kHz}$ while increasing noise from 4 to $8 \mathrm{kHz}$ by as much as $7.5 \mathrm{~dB}$ at low fan speeds. The four acoustic treatment concepts were incorporated into the bottoms of the circumferential grooves and found to provide an additional 1 to $2 \mathrm{~dB}$ sound power level reduction under $2 \mathrm{kHz}$. The sound power level reduction was found to be even greater, 2.5 to $3.5 \mathrm{~dB}$, when evaluating the reduction on rotor alone duct modes (co-rotating modes). The acoustic treatments also appeared to reduce multiple pure tone noise at transonic fan speeds. Depending on the acoustic treatment concept, the high-frequency noise created by the circumferential grooves was reduced by $\mathbf{1 . 5}$ to $5 \mathrm{~dB}$. The total noise reduction from acoustic treatments embedded into the bottoms of circumferential grooves relative to a hardwall baseline was found to be 2.5 to $3.5 \mathrm{~dB}$ sound power level. The sound power level reduction for rotor alone (co-rotating) modes was found to be 3.5 to $4.5 \mathrm{~dB}$. These results show the potential for significant turbofan noise reduction by incorporating acoustic treatments over-the-rotor.
\end{abstract}

\section{Nomenclature}

$\begin{array}{ll}\alpha & =\text { Cut-on Ratio } \\ c_{0} & =\text { Speed of Sound, } \mathrm{ft} / \mathrm{s} \\ c_{\text {std }} & =\text { Standard Day Speed of Sound, } \mathrm{ft} / \mathrm{s} \\ f & =\text { Frequency, Hz } \\ f_{c} & =\text { Corrected Frequency, Hz } \\ m & =\text { Spinning Order } \\ M & =\text { Mach Number } \\ k_{x} & =\text { Axial Wavenumber } \\ k_{0} & =\text { Ambient Wavenumber } \\ W & =\text { Sound Power Level, dB ref. } 1 \mathrm{pW} \\ \Delta P W L & =\text { Sound Power Level Difference, } \mathrm{dB}\end{array}$

\footnotetext{
* Research Aerospace Engineer, Acoustics Branch, AIAA Member.

$\dagger$ President, $1414127^{\text {th }}$ PL NE \#106, Senior Member AIAA.
} 


\section{Introduction}

A the use of air transportation continues to grow, NASA aeronautics projects have been working to develop noise reduction technologies to reduce the environmental impact of commercial aircraft. One of these noise reduction concepts, over-the-rotor acoustic treatment, has been under development for about 15 years with varying success. The noise reduction has been measured as high as $4-5 \mathrm{~dB}$ power level reduction[1], but aerodynamic performance losses have been as high as $8-10 \%[2]$.

After the last experiments with over-the-rotor treatments under NASA's Environmentally Responsible Aviation Project ended in 2015, a series of screening tests were planned to evaluate the types of liners and configurations most suitable for an over-the-rotor installation. The reduction of aerodynamic performance losses down to less than $0.75 \%$ [3] on the previous iteration is attributed to circumferential grooves installed between the fan tip and acoustic treatment that reduce the magnitude of incident dynamic pressures on the acoustic treatment. The integration of a casing treatment with an acoustic liner concept led to the name acoustic casing treatments.

In order to better understand the effects of the over-the-rotor environment on the acoustic casing treatment concepts, a series of tests were conducted from Technology Readiness Level (TRL) 1-3. For each of the acoustic casing treatment concepts, impedances were measured from $400 \mathrm{~Hz}$ to $3000 \mathrm{~Hz}$ in the Normal Incidence Tube at NASA Langley Research Center. Then, the treatments were evaluated on the Advanced Noise Control Fan (ANCF) at NASA Glenn Research Center (GRC)[4]. Finally, as discussed in this paper, the same acoustic treatments were tested in the W-8 Single Stage Axial Compressor Facility at NASA GRC. Since the W-8 facility is an internal flow fan performance facility, an inlet in-duct array was designed and utilized to measure in-duct sound power levels to evaluate the noise reduction potential of the acoustic casing treatments.

\section{Experiment}

\section{A. W-8 Single Stage Axial Compressor Facility}

The test was conducted in the W-8 Single-Stage Axial Compressor Facility at the NASA Glenn Research Center. A schematic of the facility is shown in Fig. 1. The facility is capable of delivering up to 7,000 hp at speeds up to $21,240 \mathrm{rpm}$ to a 22". fan or compressor. Up to $100 \mathrm{lbm} / \mathrm{s}$ of air is provided from an atmospheric inlet. Flow conditioning screens in the inlet plenum reduce the turbulence intensity at the fan to less than $1 \%[5]$. The flow through the facility is controlled by a sleeve throttle valve. The air can be exhausted through an atmospheric exhaust system or an altitude exhaust system. Facility instrumentation can include up to 400 channels of steady pressure and thermocouple measurement, tip clearance sensing, and up to 96 channels of high speed rotating fan data.

\section{B. High Bypass Ratio Turbofan Rotor (R4)}

The Source Diagnostic Test (SDT) fan rotor was utilized for evaluating over-the-rotor (OTR) acoustic casing treatments. The fan, designated R4, was designed by General Electric Aircraft Engines and is a 1/5 scale model of a high bypass ratio turbofan. The fan model has a 22" diameter with 22 titanium blades and a design speed of 12,657 rpmc. This fan was chosen for its titanium blades, since over-the-rotor treatments have been shown to damage composite blades [6]. A significant amount of aerodynamic and acoustic experimental data has been acquired with this fan model with to evaluate the effects of fan exit guide vanes, tip clearance[7], and rotor sources [8, 9], as well as prior test experience in the W-8 facility [3, 5].

\section{Over-the-Rotor Fan Case Configurations}

A total of six configurations were tested in W-8, matching those that were tested on the ANCF[4]. Two baseline fan cases and four treated fan cases were used to isolate the casing treatment effects from the acoustic treatment effects as depicted in Fig. 22 The first configuration was a hardwall baseline fan case. Since circumferential grooves have been incorporated into the previous configurations [1, 3], a hardwall configuration with circumferential grooves was also tested. This configuration allows for the separation of the impact of the grooves from the impact of the treatment. All configurations consist of sheets of Garolite G10 cut into rings and layered axially to create a fan casing as shown in Fig. 4 Six rows of circumferential grooves covered the fan chord in the axial direction. Each circumferential groove is $1 / 2$ " deep and 1/4" wide with 1/8" wide rib in between, as shown in the center of Fig. 2 . In the bottoms of the grooves, the four treated fan case configurations had 0.035 " diameter perforate holes with $10 \%$ open area leading to various acoustic treatments. The four treated configurations, shown in Fig. 3, consisted of one with 0.06" perforate thickness 


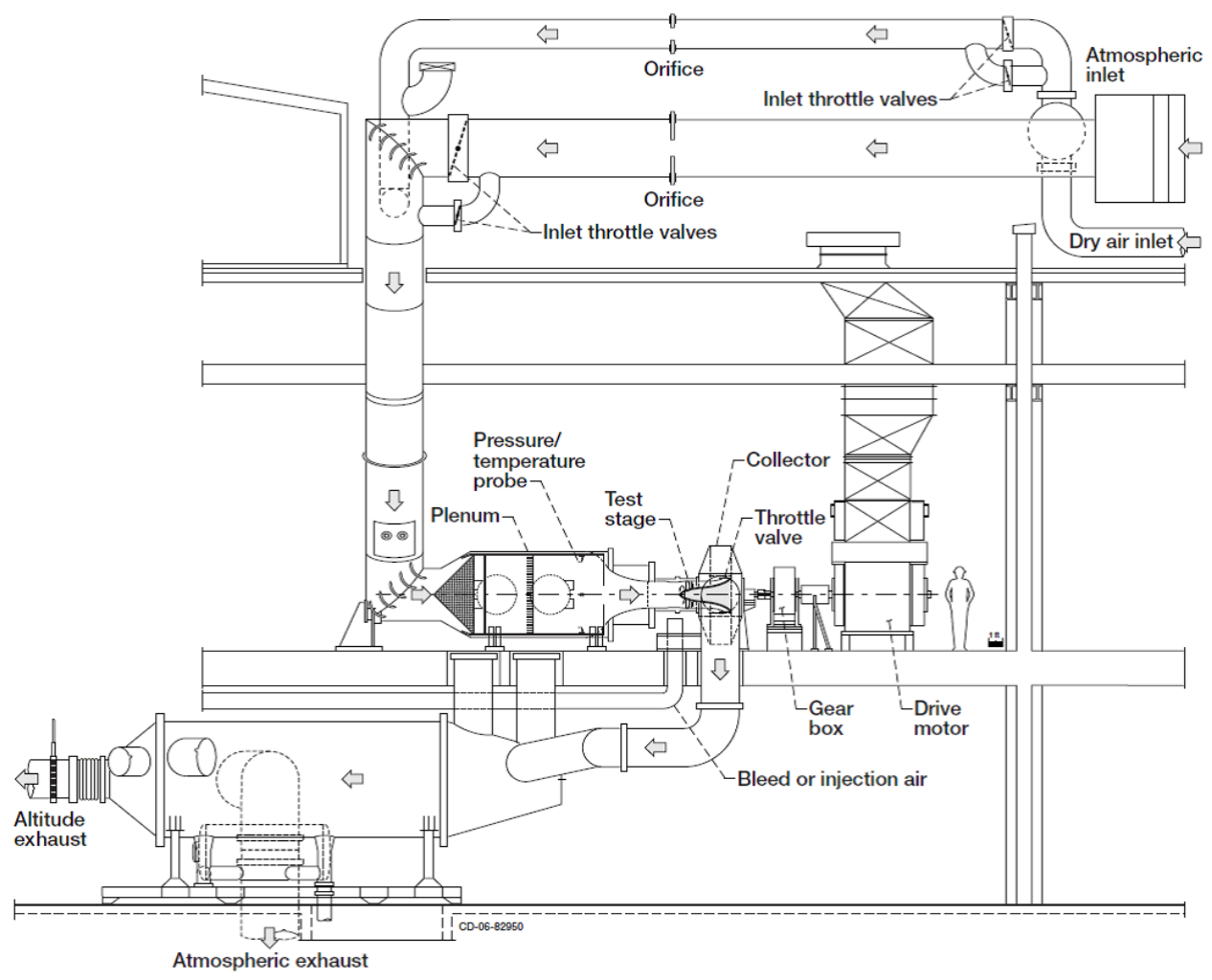

Fig. 1 Schematic of the W-8 Single Stage Axial Compressor Facility at the NASA Glenn Research Center.

and empty 1" deep chambers, one with a 1/4" perforate thickness and 1" deep empty chamber, one matching the empty chamber geometry with 80ppi $8 \% \mathrm{FeCrAlY}$ metal foam in the chambers, and one with fins in the chambers to provide expansion of high amplitude pressure waves. The treatments were segmented into $1 / 2$ " width chambers, but repeated circumferentially around the duct. The peak attenuation for each of the acoustic treatments was measured between 2000 $\mathrm{Hz}$ to $2500 \mathrm{~Hz}$. While all of the grooved fan cases had a hot tip clearance just under 0.020 ", the hardwall baseline hot tip clearance was $0.038 "$.

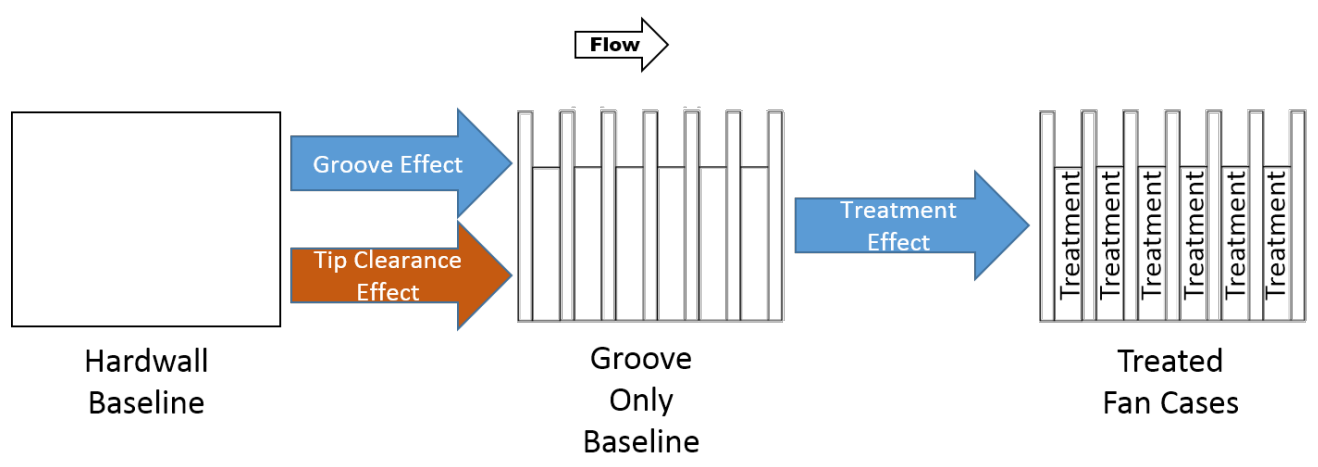

Fig. 2 Over-the-Rotor Fan Case Effects. 


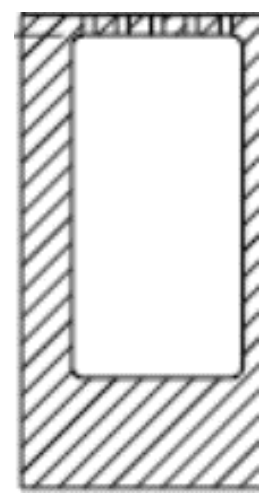

(a)

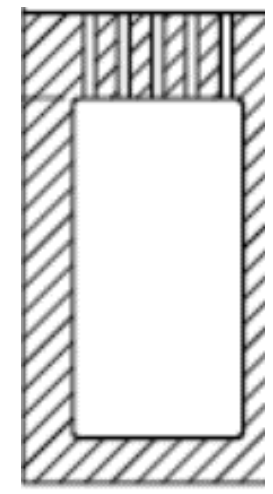

(b)

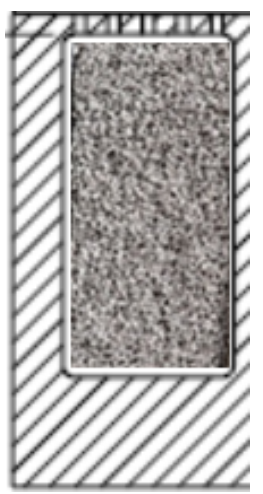

(c)

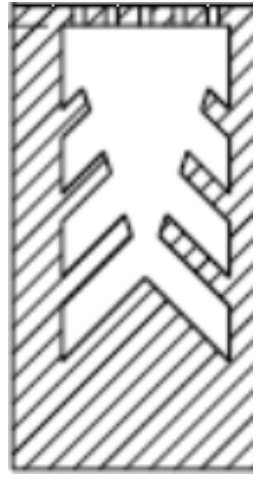

(d)

Fig. 3 Cross-sections of the acoustic treatments (flow direction is into the page), (a) Empty Chamber Treatment, (b) Thick Perforate Treatment, (c) Foam Metal Treatment, and (d) Expansion Chamber Treatment.

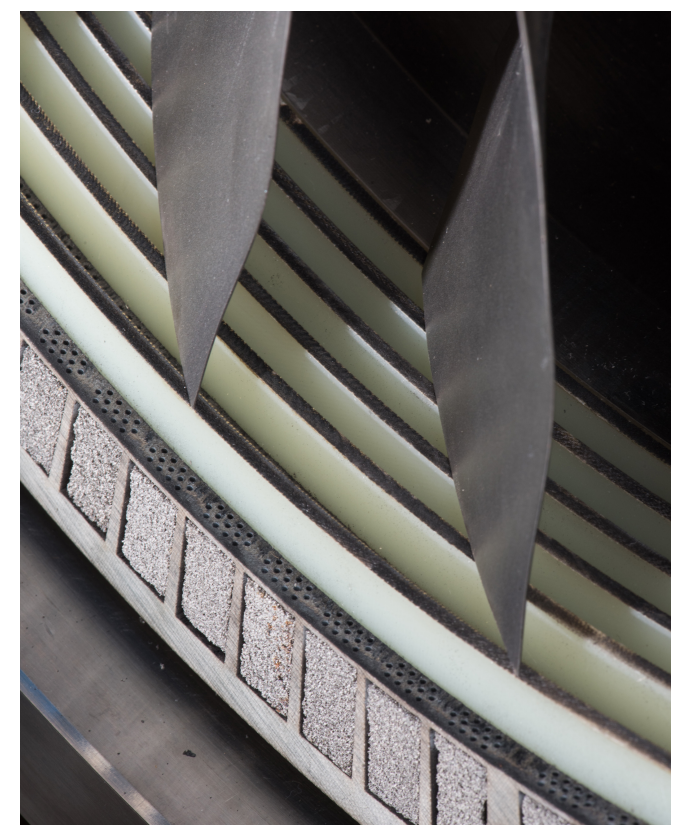

Fig. 4 View of the layered over-the-rotor acoustic casing treatment installed into a fan case over the R4 rotor.

\section{Inlet In-duct Array Instrumentation}

While the internal flow facility is adequate for fan performance measurements, traditional far-field acoustic measurements cannot be obtained. In order to obtain insight into the acoustic performance of fan model hardware an inlet in-duct array was designed and fabricated to measure in-duct acoustic levels in the W-8 facility. The array, shown in Fig. 5. has 128 potential sensor locations arranged in two axial arrays with a $1 / 2 "$ axial spacing, and a circumferential array with a $4^{\circ}$ spacing, at a constant diameter of $22 \mathrm{in.}$ The circumferential array is located about $24 "$ upstream from the fan. The long axial array spans from about 24" to 10" upstream of the fan. For the testing described, a subset of 85 sensors containing half of the circumferential array and both axial arrays were utilized[10]. The sensors used were Kulite ${ }^{\circledR}$ XCS-133-093-25A pressure transducers with a 25 psia range. The sensors were installed into 1/8 in. stainless-steel tubes and then installed into nylon adapters. The Kulite ${ }^{\circledR}$ pressure transducers were calibrated with a Brüel \& Kjær Multifunction Acoustic Calibrator (Type 4226) generating a Sound Pressure Level (SPL) of 114 dB at $1 \mathrm{kHz}$. 


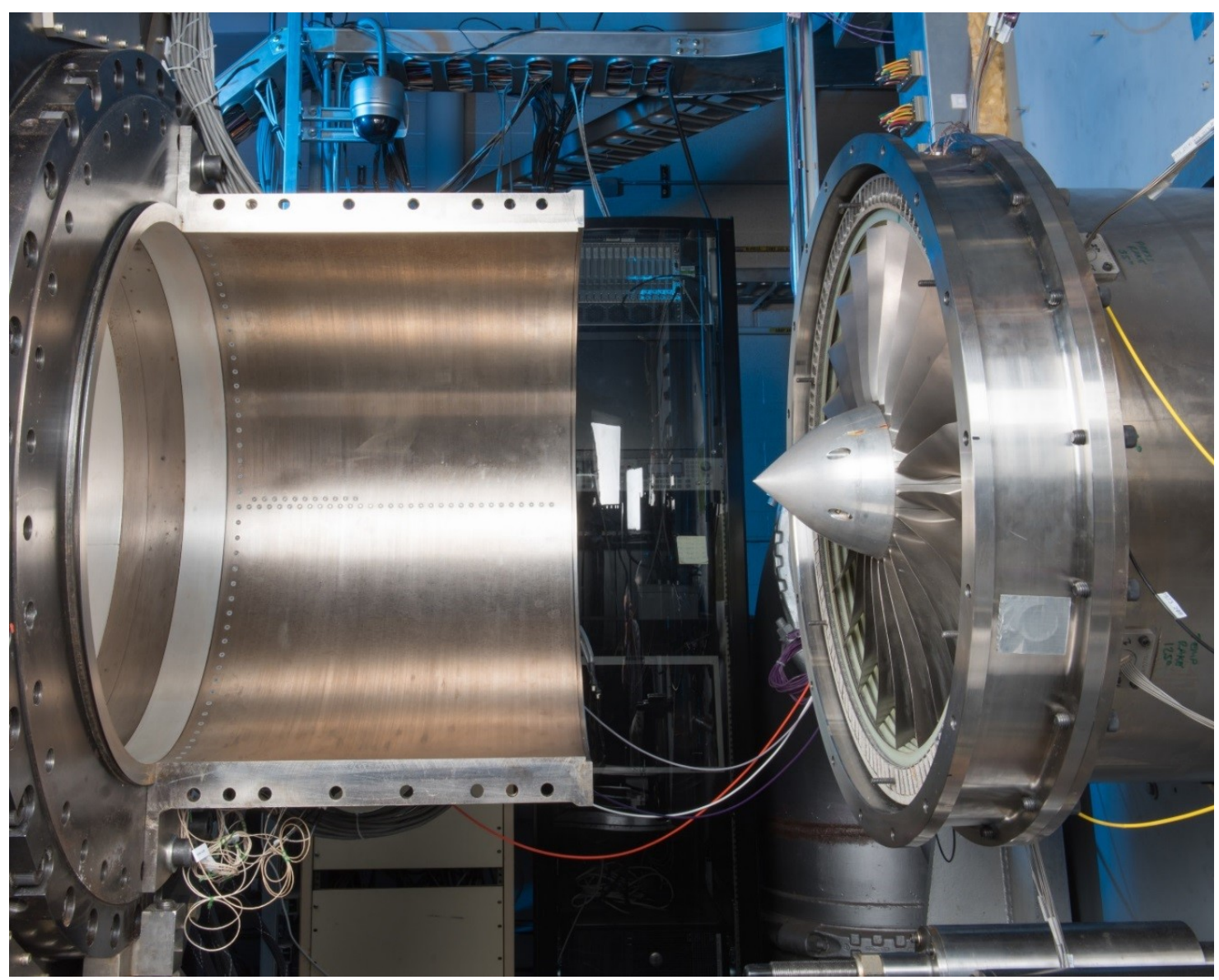

Fig. 5 The inlet in-duct array and R4 fan installed in the W-8 Single Stage Axial Compressor facility.

\section{E. Test Execution}

Data was obtained at nine fan operating conditions chosen to correspond with those used in prior tests[5, 8]. These conditions are on the nominal operating line with corrected fan speeds and corrected mass flows shown in Table 1. For each condition, the Mach number over the in-duct array was calculated from static pressure measurements in the array case. The fan inlet Mach number was then calculated using the area change between the array and the fan leading edge and assuming uniform flow. Fan inlet axial Mach number combined with the tangential Mach number based on fan rotation speed at the blade tip were used to calculate a fan tip Mach number. The fan is subsonic up through $80 \%$ speed and supersonic from $87.5 \%$ to $100 \%$ speed. Prior to obtaining acoustic measurements, fan exit aerodynamic instrumentation were removed to prevent unwanted noise sources.

\section{In-duct Array Data Processing and Validation}

In this section, a methodology for processing the W-8 inlet in-duct array acoustic data to extract sound power level differences is presented. Since this test was the first use of an inlet in-duct array for acoustic measurements in the W-8 facility, data repeatability and validation with comparisons with existing data are shown.

\section{A. Acoustic Data Processing}

The inlet in-duct array acoustic data was obtained by recording 10 seconds of data at sample rate of $96 \mathrm{kHz}$ for each condition in Table 1 The time-series data were interpolated to adjust the sample rate for speed of sound variations with a cubic spline interpolation. This interpolation accounts for day-to-day speed of sound variations to align the resultant spectra based on wavenumber. The data was then decimated by a factor of 2 and cross-spectral matrices were calculated with 2048 sample windows to give a frequency bin width of $23.4 \mathrm{~Hz}$. The result of the time-series interpolation is in an 
Table 1 Set Point and Inlet Conditions on the Nominal Operating Line

\begin{tabular}{|c|c|c|c|c|c|c|}
\cline { 2 - 7 } \multicolumn{1}{c|}{} & \multicolumn{3}{c|}{ Set Point Conditions } & \multicolumn{3}{c|}{ Inlet Conditions } \\
\hline & $\begin{array}{c}\text { \% Fan } \\
\text { Speed }\end{array}$ & $\begin{array}{c}\text { Corrected } \\
\text { Fan Speed, } \\
\text { rpmc }\end{array}$ & $\begin{array}{c}\text { Corrected } \\
\text { Mass Flow, } \\
\text { lbm/sec }\end{array}$ & $\begin{array}{c}\text { Inlet Array } \\
\text { Mach }\end{array}$ & $\begin{array}{c}\text { Fan Inlet } \\
\text { Axial } \\
\text { Mach }\end{array}$ & $\begin{array}{c}\text { Fan Tip } \\
\text { Mach }\end{array}$ \\
\hline 1 & $50.0 \%$ & 6,329 & 46.9 & 0.212 & 0.236 & 0.596 \\
2 & $60.0 \%$ & 7,594 & 56.2 & 0.256 & 0.286 & 0.718 \\
3 & $61.7 \%$ & 7,809 & 57.8 & 0.264 & 0.296 & 0.739 \\
\hline 4 & $70.0 \%$ & 8,860 & 65.9 & 0.305 & 0.343 & 0.843 \\
5 & $77.5 \%$ & 9,809 & 73.4 & 0.344 & 0.389 & 0.940 \\
6 & $80.0 \%$ & 10,126 & 75.9 & 0.359 & 0.407 & 0.974 \\
\hline 7 & $87.5 \%$ & 11,075 & 83.7 & 0.404 & 0.460 & 1.075 \\
9 & $95.0 \%$ & 12,024 & 91.8 & 0.455 & 0.523 & 1.183 \\
\hline
\end{tabular}

alignment of the spectra based on standard day speed of sound to corrected frequencies. Corrected frequency is defined as the correction of frequency to standard day conditions, as below in Eq. (1) where $c_{0}$ is the speed of sound, $c_{s t d}$ is the standard day speed of sound.

$$
f_{c}=f c_{0} / c_{s t d}
$$

The cross-spectral matrices are then processed using OptiNav Inc.'s Beamform Interactive. A detailed description of the processing is provided by Dougherty[11]. For each corrected frequency, the cross-spectral matrix is processed with steering vectors and Quantitative Beamforming to a $2 \mathrm{D}$ grid of spinning order $(m)$ versus axial wavenumber $\left(k_{x} / k_{0}\right)$. The vertical axis is converted from axial wavenumber $\left(k_{x} / k_{0}\right)$ to cuton ratio $(\alpha)[12]$ with Eq. [2], as shown below. The peak sound pressure levels (SPL ref. $20 \mu \mathrm{Pa}$ ) are identified and converted to sound power level (PWL ref. 1pW).

$$
\alpha= \pm \sqrt{1-\left(1-M^{2}\right)\left(\frac{k_{x}}{k_{0}}\right)^{2}}
$$

The result of this processing is a map of duct modes and their sound power level at each frequency. This allows for the in-duct sound field to be decomposed to evaluate the impact of treatments on a subset of the measured duct modes. A sample mode map is shown in on the left of Fig. 6 The modes from the top half of the map $(0>\alpha \geq 1)$, refer to aft propagating modes, while the bottom half $(-1 \geq \alpha>0)$, refer to forward propagating modes. Positive spinning modes $(m>0)$ are co-rotating with the fan, and negative spinning modes $(m<0)$ are counter-rotating, and plane waves are found at $m=0$. By integrating the sound power in a subset of the mode map at each frequency, we can determine the relative contributions of duct noise sources. This modal decomposition is shown on the right of Fig. 6 for the hardwall configuration at $50 \%$ fan speed. The total power is dominated by forward propagating power, therefore, facility inlet noise is not a concern at frequencies less than $10 \mathrm{kHz}$. Plane waves are dominant at frequencies under $800 \mathrm{~Hz}$ since only plane waves are cut-on at low frequencies. Between $100 \mathrm{~Hz}$ and $3500 \mathrm{~Hz}$, the total power spectrum is a combination of co-rotating and counter-rotating duct modes. Above $3500 \mathrm{~Hz}$, the total in-duct sound power level is dominated by forward propagating and co-rotating modes. By subtracting treated configuration sound power levels from hardwall configuration mode sound power levels, treatment effectiveness can be evaluated on a modal basis. 

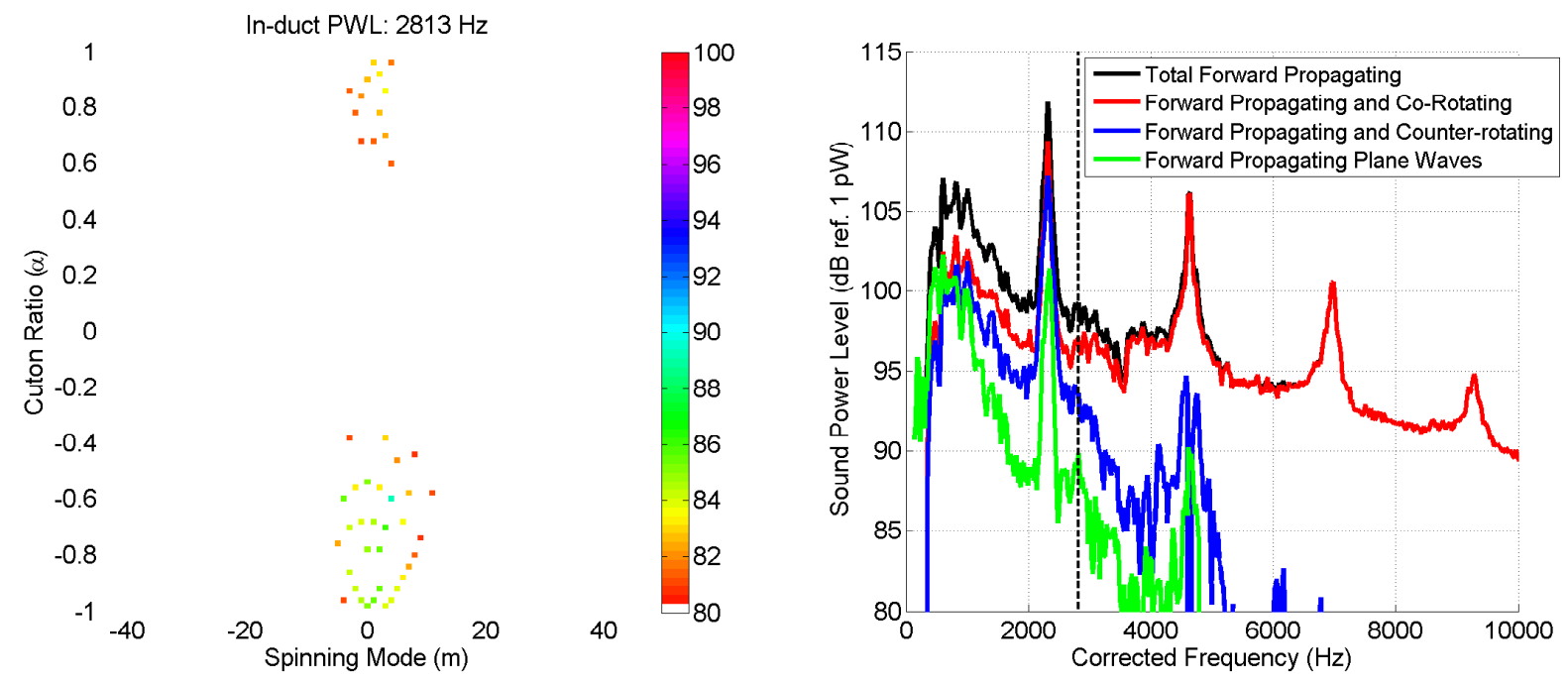

Fig. 6 In-duct Modal Decomposition for the hardwall fan case at $50 \%$ Speed; (left) mode map at $2813 \mathrm{~Hz}$, and (right) sound power level breakdown of forward propagating modes.

\section{B. In-duct Modal Sound Power Repeatability}

The groove only configuration was tested towards the beginning of testing and repeated towards the end of testing (about a month apart). The repeat was included to give a qualitative assessment of the repeatability of set point conditions, fan case installation, and their impact on the measurement of the inlet in-duct sound field. The repeatability of inlet in-duct sound power level for the fan conditions in Table 1 1is shown in Fig. 7. The repeatability of in-duct PWL measurements is within $\pm 1 \mathrm{~dB}$ with a few exceptions; very low frequency $(150 \mathrm{~Hz})$ noise at the $61.7 \%$ speed condition, and high frequency $(10 \mathrm{kHz})$ MPT noise at $95 \%$ speed. This provides confidence in the measurement of sound power level differences greater than $1 \mathrm{~dB}$.

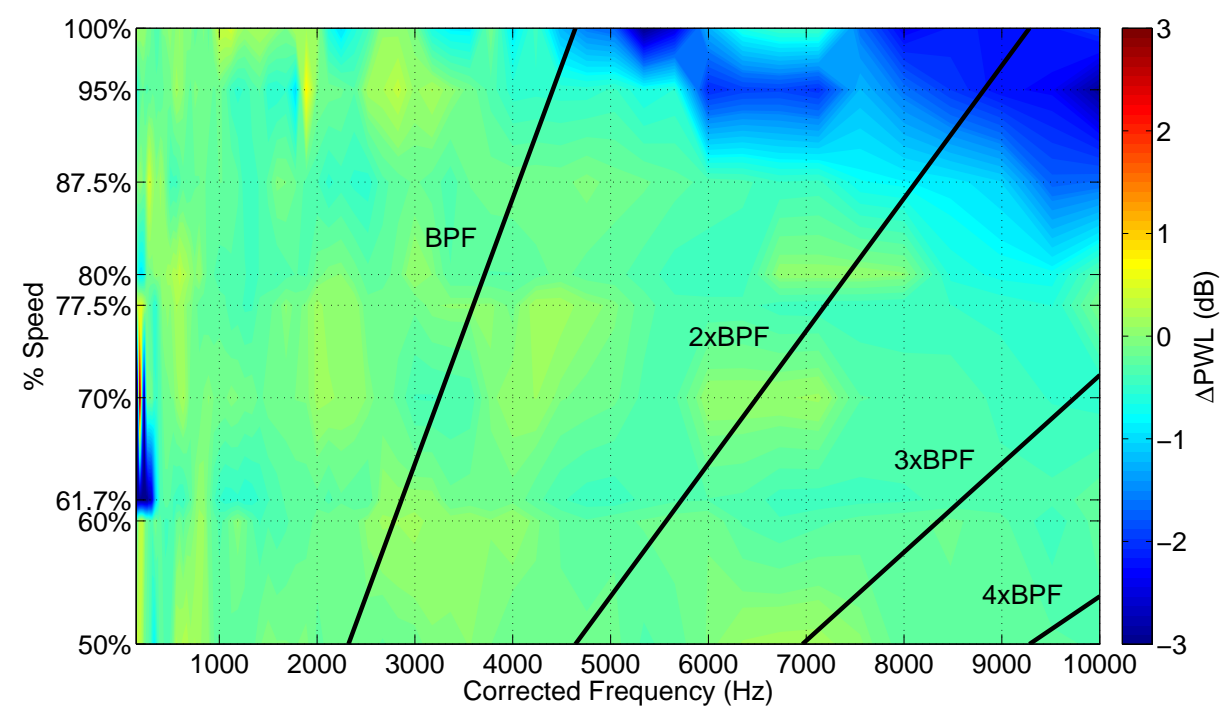

Fig. 7 Repeatability of the measurement of forward propagating 1/12 octave sound power levels (groove only fan case). 


\section{Source Diagnostic Test (SDT) Rotor Alone Nacelle (RAN) Comparison[13]}

The Source Diagnostic Test (SDT) in the 9x15 Low Speed Wind Tunnel at NASA GRC included a Rotor Alone Nacelle (RAN) configuration to measure rotor alone noise separate from that of the rest of the propulsor[8]. This test utilized the same 22" diameter R4 turbofan rotor used for the acoustic casing treatment testing in W-8. During this test, inlet in-duct acoustic data were acquired on a $1 / 2$ circle array of 60 equally spaced sensors a few inches upstream from the fan[13]. Although there are geometry differences between RAN flight inlet and W-8 inlet bellmouth, the rotor noise sources should be similar.

A sound pressure level (SPL) spectral comparison of the average in-duct sensor from the SDT RAN test and the W-8 test is shown in Fig. 8. Background exhaust noise was discovered (two broadband humps around $800 \mathrm{~Hz}$ and $4000 \mathrm{~Hz}$ ) in W-8 by running the rig with and without the exhaust throttle valve choked. The exhaust noise was subtracted from the W-8 baseline data to give the solid blue line. The most notable difference is that the Blade Passing Frequency (BPF) tones are cut-on and broad in the W-8 data, while they are not cut-on in the SDT RAN data. This is believed to be due to the boundary layer turbulence length-scale differences (and their interaction with the fan) between the W-8 straight bellmouth and a flight inlet[14, 15]. While rotor blade sources should appear in a co-rotating spinning mode at the blade count, turbulence rotor interaction can cut-on lower order modes. Overall, the sound pressure levels are about $3 \mathrm{~dB}$ louder in W-8 from $250 \mathrm{~Hz}$ to about $6.5 \mathrm{kHz}$. At high frequencies, the W-8 data rolls off quicker due to an anti-aliasing filter applied to the W-8 data with a cut-off frequency of $8.4 \mathrm{kHz}$. The spectral similarities, aside from the cut-on BPF tones, give confidence that the correct rotor alone noise sources are being measured in W-8.

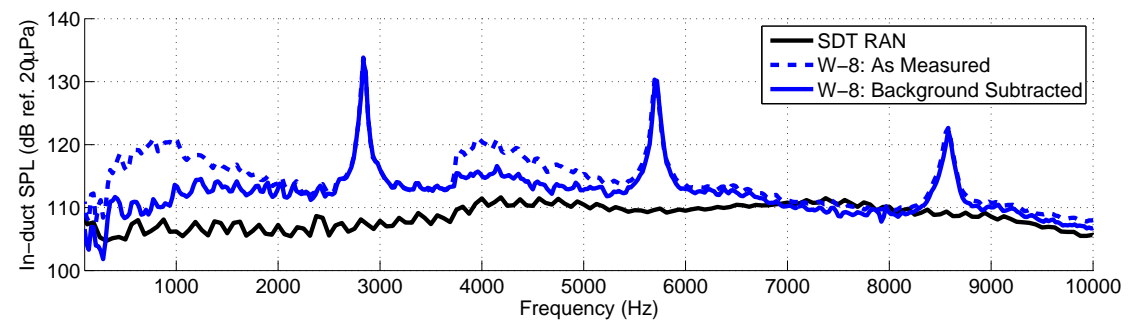

Fig. 8 Comparison of average in-duct SPL between SDT RAN and W-8 at 61.7\% speed.

A modal SPL comparison between the SDT RAN and W- 8 arrays at the $61.7 \%$ speed condition is shown in Fig. 9 The modal comparison was created by taking the 2-D Discrete Fourier Transform of the inlet circumferential array [16] with diagonal deletion in the cross-spectral matrices[17]. The appearance of sound in cut-off modes in the SDT RAN data at low frequencies (wavelengths less than $1 / 2$ fan diameter) is believed to be due to the closeness of the SDT RAN array to the fan (a few inches). Over this distance cut-off modes have not had the required length to decay. When measured by the W-8 array (about 1 fan diameter upstream from the fan) they have decayed. The other notable difference is that the W-8 BPF tones are cut-on. Rotor alone noise is dominated by co-rotating modes near the cut-on boundary.

\section{Noise Reduction Results}

The impact of circumferential grooves and acoustic treatments over-the-rotor are evaluated by comparing the differences in measured in-duct sound power levels between the fan case configurations tested, as depicted in Fig. 2 . If we assume the effects are independent, the impact of circumferential grooves and acoustic treatment can be evaluated separately and then combined to evaluate the net benefits. The difference between the hardwall fan case and one with circumferential grooves is evaluated to determine the effect of circumferential grooves on in-duct sound power levels. Unfortunately, there was also a tip clearance difference between these two fan cases. The effect of this tip clearance difference alone is approximated with far-field low speed wind tunnel data[7]. Then, the impact of acoustic treatments is determined by evaluating the difference in in-duct power levels from the circumferentially grooved case from the circumferentially grooved fan cases with acoustic treatments. The results are presented as contour maps of 1/12 octave in-duct sound power level for the conditions in Table 1 from $100 \mathrm{~Hz}$ to $10 \mathrm{kHz}$. Finally, the total noise reduction is evaluated as the combination of the groove effect and treatment effect. 


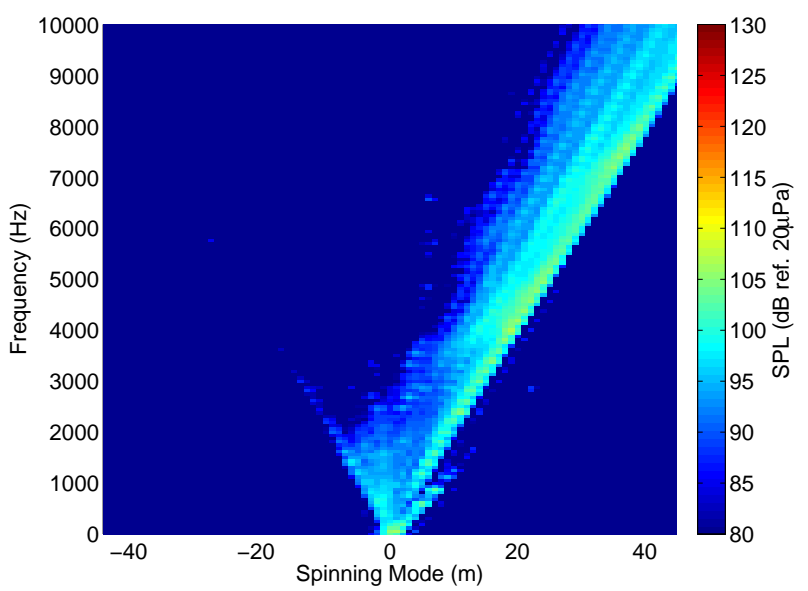

(a) SDT RAN [13]

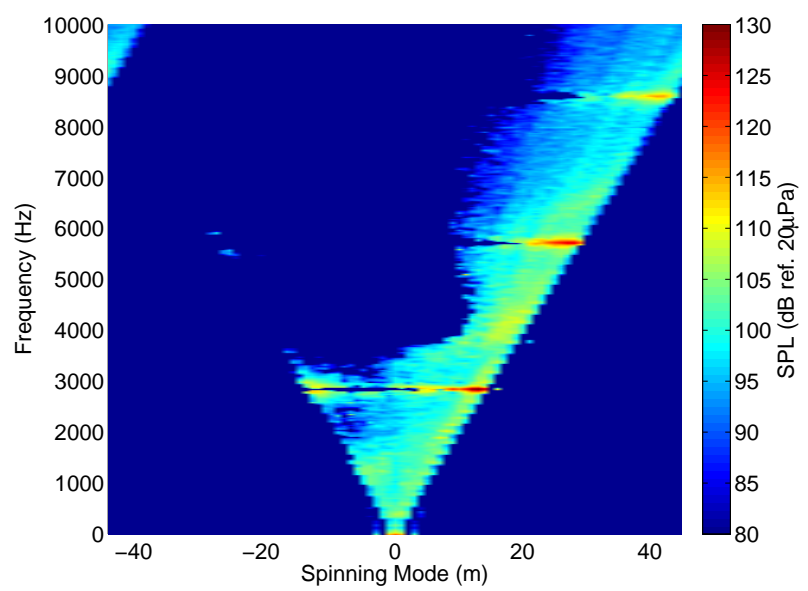

(b) W-8 Background Subtracted

Fig. 9 Comparison of in-duct modal SPL between (a) SDT RAN and (b) W-8 background subtracted at 61.7\% speed.

\section{A. Effect of Tip Clearance}

In 2002, the Source Diagnostic Test Rotor Alone Nacelle configuration was tested in the 9x15 Low Speed Wind Tunnel at NASA Glenn Research Center to determine the impact of varying rotor tip clearance[7]. Far-field acoustic data were obtained with nominal (0.000"), 0.020", and 0.030" tip clearances and presented as sound power levels integrated over all observer angles. The far-field acoustic effect of a larger tip clearance was found to be as high as $2 \mathrm{~dB}$ sound power level. Since inlet and aft rotor alone noise were included in this assessment, the data were reprocessed to extract only inlet radiated power levels to evaluate the impact on forward radiated noise. The effect of the tip clearance difference is defined in Eq. 3. Fig. 10 shows the effect of a decrease from 0.030" to a nominal (0.000") tip clearance on inlet radiated 1/12 octave sound power level. The $0.030 "$ tip clearance fan case generates approximately $1 \mathrm{~dB}$ PWL more than the nominal fan case at frequencies greater than $2 \mathrm{kHz}$ and at fan speeds less than $70 \%$. The tip clearance difference causes a slight change to the onset of multiple pure tone (MPT) noise at the $85 \%$ speed, but is otherwise a relatively small effect.

$$
\Delta P W L_{t i p}=W_{0.000 "}-W_{0.030}
$$

\section{B. Effect of Circumferential Grooves}

The effect of circumferential grooves is evaluated by examining the difference between in-duct sound power levels between the circumferentially grooved fan case and the hardwall fan case. Since there is a tip clearance difference between these two fan cases, a $1 \mathrm{~dB}$ reduction in noise above $2 \mathrm{kHz}$ for fan speeds under $65 \%$ is expected. The effect of circumferential grooves is defined in Eq. 4. The effect of both circumferential grooves and tip clearance is shown in Fig. 11. Circumferential grooves appear to reduce in-duct sound power levels by about $1.5 \mathrm{~dB}$ between $1-2 \mathrm{kHz}$ at fan speeds under 77.5\%. The largest effect of circumferential grooves appears to be an increase of up to 7dB PWL around 3xBPF and $4 \mathrm{xBPF}$. This increase is largest at the lowest speed tested (50\%) and reduces as fan speed increases to $77.5 \%$ where it no longer exists. The effect of circumferential grooves on MPT noise is relatively small.

$$
\Delta P W L_{\text {grooves }}=W_{\text {grooves }}-W_{\text {hardwall }}+\Delta P W L_{\text {tip }}
$$




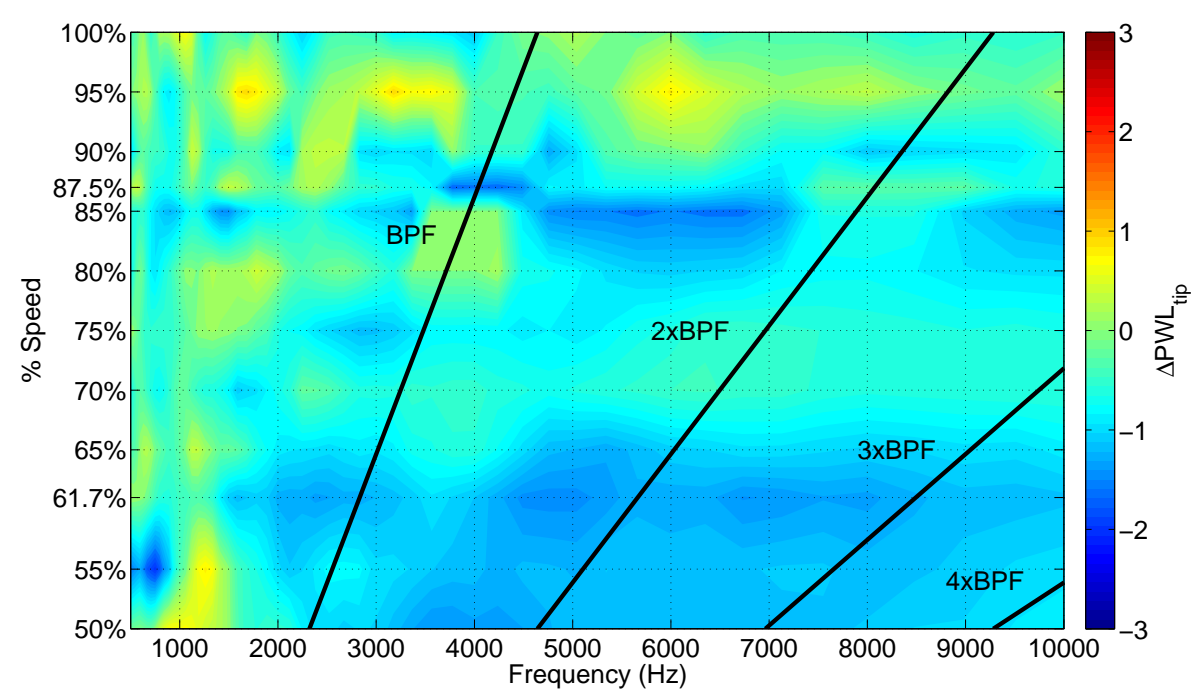

Fig. 10 The effect of tip clearance on $1 / 12$ octave far-field inlet radiated sound power level $(0.000$ " clearance - 0.030" nominal clearance)[7]. Negative numbers (blue) are a noise reduction, while positive (red) are a noise increase.

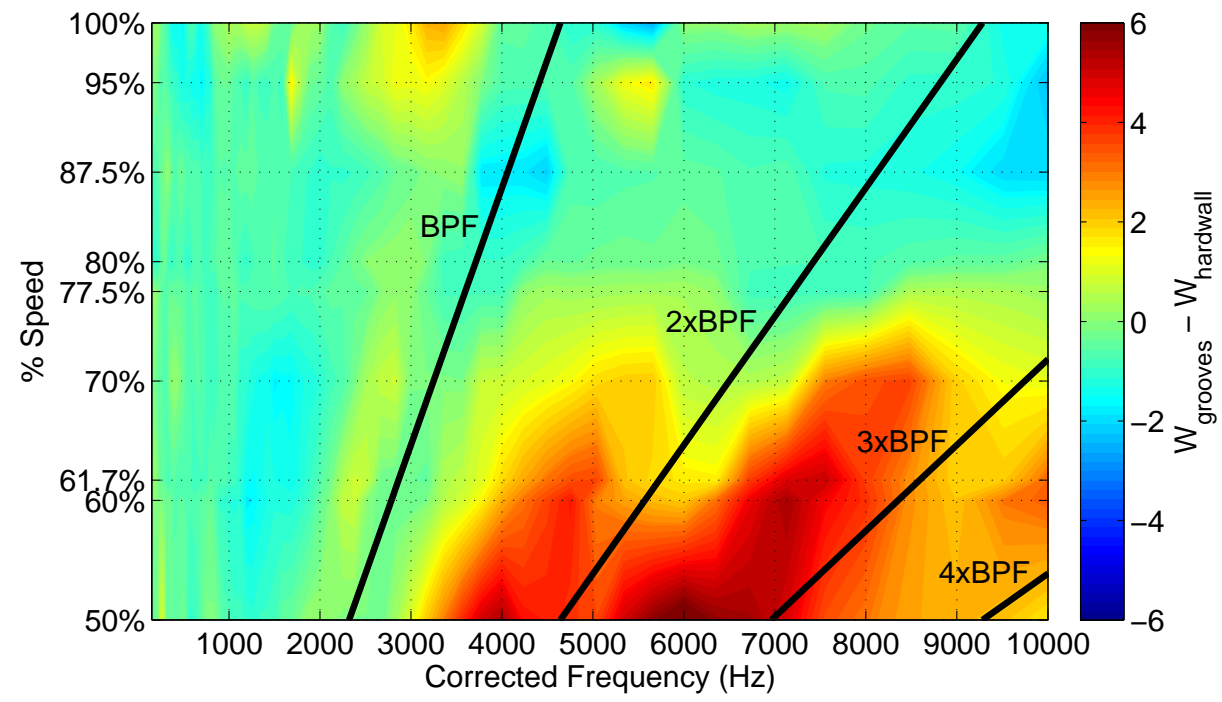

Fig. 11 The effect of circumferential grooves and tip clearance difference on forward propagating 1/12 octave inlet in-duct PWL (ref. hardwall). Negative numbers (blue) are a noise reduction, while positive (red) are a noise increase. 


\section{Acoustic Treatment Noise Reduction}

The impact of adding acoustic treatment to the bottoms of circumferential grooves is evaluated by subtracting the measured in-duct sound power level of a treated fan case from the groove only baseline fan case as shown in Eq. 5 . The resultant noise reduction in 1/12 octave bands for the fan conditions in Table 1 is shown in Fig. 12. Each of the acoustic treatments showed 1-2dB PWL reduction in forward propagating modes from $500 \mathrm{~Hz}$ to $1500 \mathrm{~Hz}$. The frequency of peak reduction decreases with increasing fan speed. The treatments provided broad noise reduction, except for the thick perforate treatment which provided a higher peak noise reduction but over about half the frequency range. The increase in noise (up to $7 \mathrm{~dB}$ ) around $2 \mathrm{xBPF}$ and $3 \mathrm{xBPF}$ due to the circumferential grooves was reduced by the treatments by $1-5 \mathrm{~dB}$. While the thick perforate treatment provided the greatest peak reduction, it had very little impact on the additional circumferential groove noise. Above $87.5 \%$ speed, the in-duct sound power spectrum is dominated by multiple pure tones (MPTs). When the fan tip speed is sonic, MPTs appear between BPF tones and increase in strength as fan speed continues to increase. The tones are centered at $1 / 2 \mathrm{BPF}$ and its harmonics. The treatments appear to delay the onset of these tones at the $95 \%$ speed resulting in a reduction of as much as $5 \mathrm{~dB}$ for the empty chamber treatment, while increasing the $1 \mathrm{xBPF}$ and $2 \mathrm{xBPF}$ tones by about $1.5 \mathrm{~dB}$.

$$
\Delta P W L_{\text {treatment }}=W_{\text {treatment }}-W_{\text {grooves }}
$$

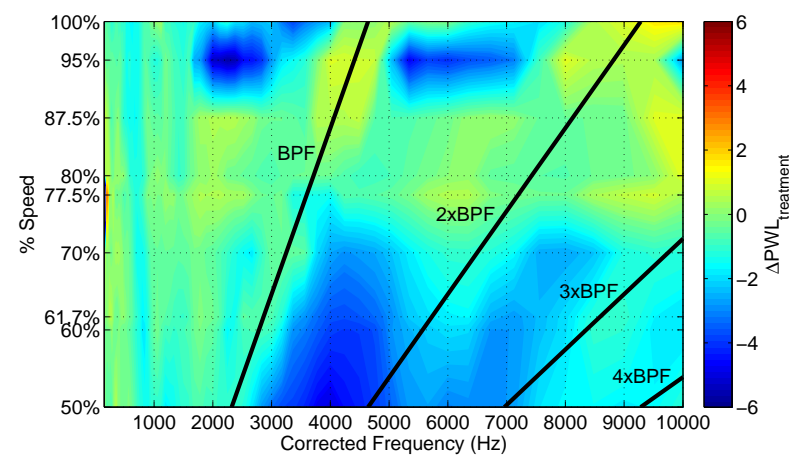

(a) Empty Chamber Treatment

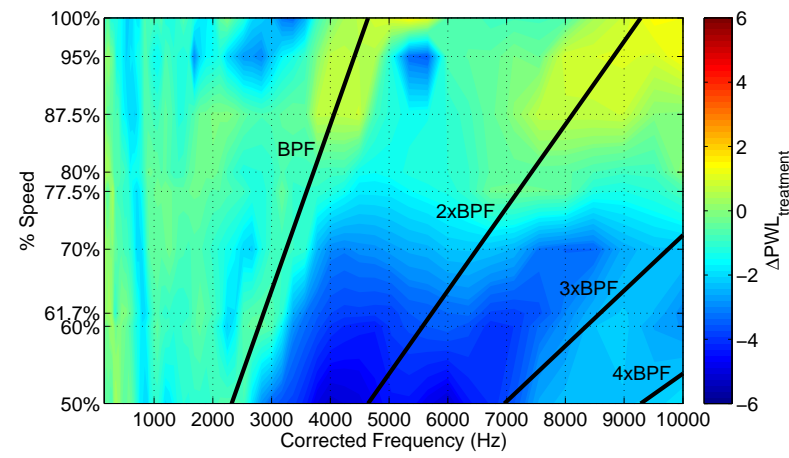

(c) Foam Metal Treatment

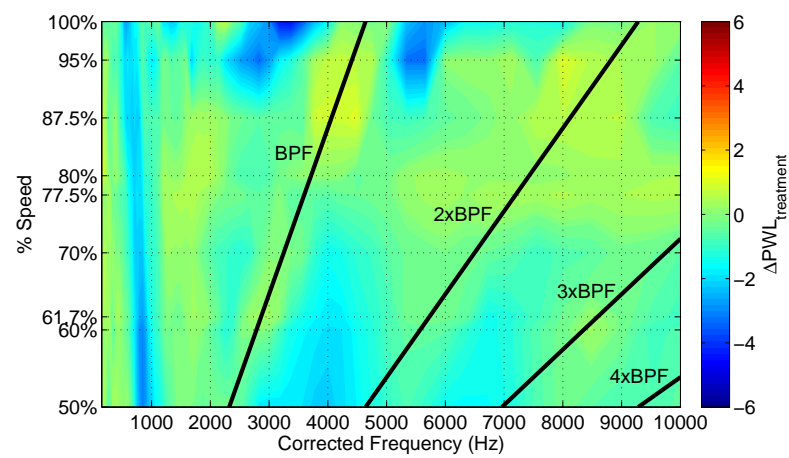

(b) Thick Perforate Treatment

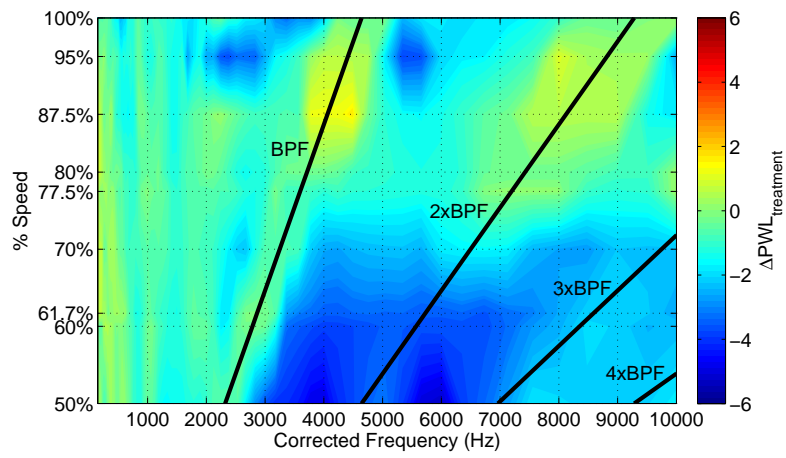

(d) Expansion Chamber Treatment

Fig. 12 Impact of acoustic treatments on forward propagating 1/12 octave in-duct PWL (dB ref. grooved fan case) for each of the acoustic treatments (a) Empty Chamber Treatment, (b) Thick Perforate Treatment, (c) Foam Metal Treatment, and (d) Expansion Chamber Treatment. Negative numbers (blue) are a noise reduction, while positive (red) are a noise increase.

Since rotor alone noise is dominated by co-rotating modes, the data was processed to extract the noise reduction in co-rotating modes for the four treatments. The reduction in co-rotating duct modes for each of the four acoustic treatments is shown in Fig. 13. The reduction in co-rotating modes is about $2-3 \mathrm{~dB}$, or $1 \mathrm{~dB}$ greater than the reduction to all forward propagating modes. 


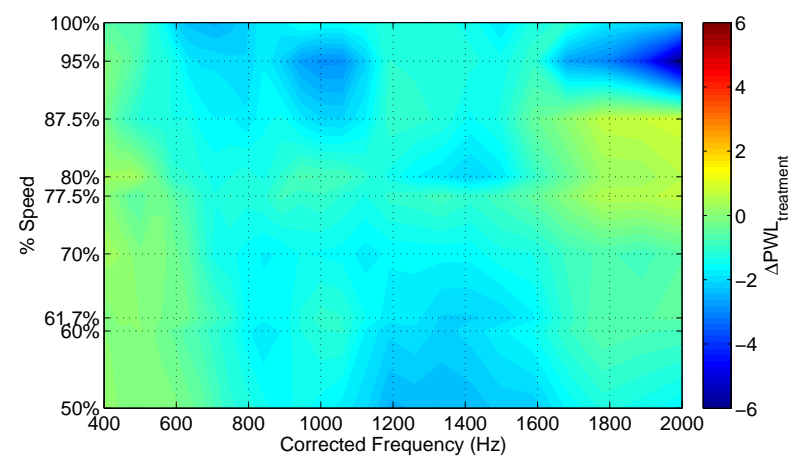

(a) Empty Chamber Treatment

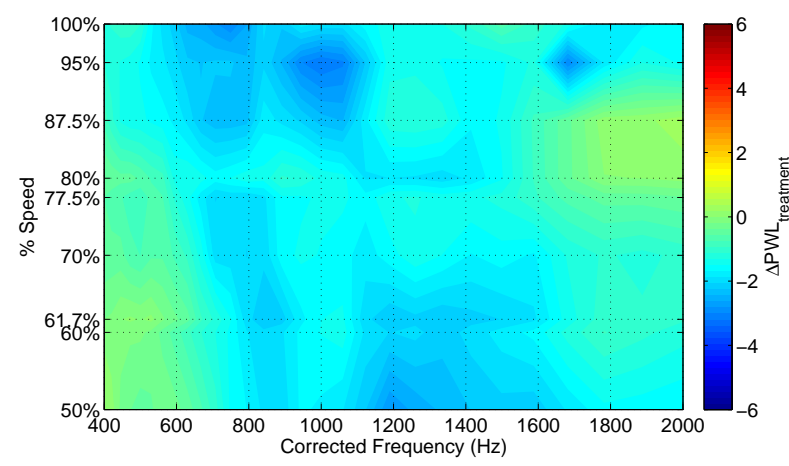

(c) Foam Metal Treatment

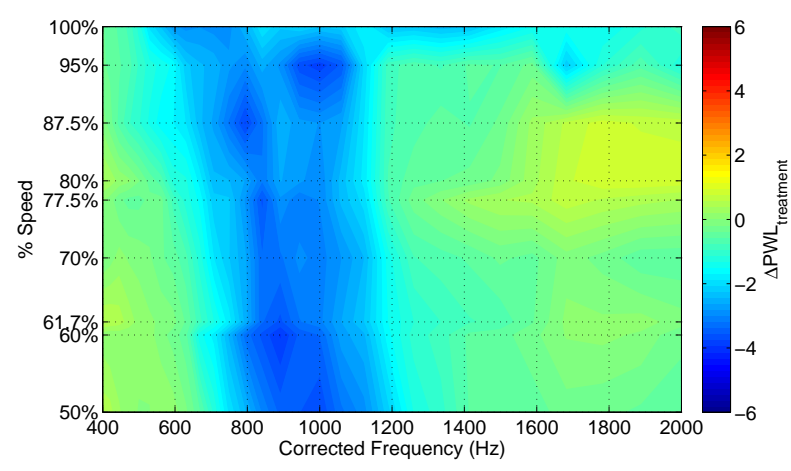

(b) Thick Perforate Treatment

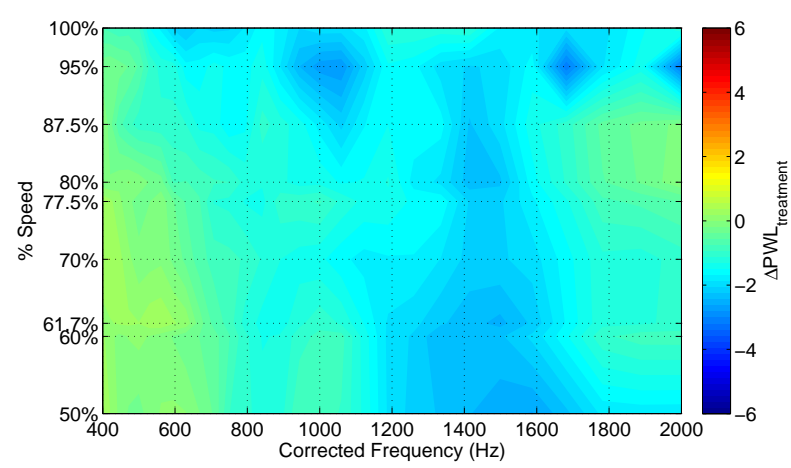

(d) Expansion Chamber Treatment

Fig. 13 Impact of acoustic treatments on co-rotating forward propagating 1/12 octave in-duct PWL (dB ref. grooved fan case) for each of the acoustic treatments (a) Empty Chamber Treatment, (b) Thick Perforate Treatment, (c) Foam Metal Treatment, and (d) Expansion Chamber Treatment. Negative numbers (blue) are a noise reduction, while positive (red) are a noise increase.

\section{Total Noise Reduction}

In order to evaluate the expected noise reduction from adding an over-the-rotor acoustic casing treatment to a conventional fan, the combination of the casing treatment effect and acoustic treatment effect, as defined in Eq. 6 . should be considered. Circumferential grooves were found to reduce noise between $1-2 \mathrm{kHz}$ by up to $1.7 \mathrm{~dB}$, while increasing noise around $2 \mathrm{XBPF}$ and $3 \mathrm{xBPF}$ by up to $7.6 \mathrm{~dB}$. Both of these effects are greatest at the lowest speeds and diminish as fan speed is increased. The acoustic treatments were effective at reducing the PWL of co-rotating modes by $2-3 \mathrm{~dB}$, as well as reducing the circumferential groove noise by $1.5-5 \mathrm{~dB}$. The effects result in a total noise reduction of 2.6-3.6dB to forward propagating modes (and 3.5-4.6dB to co-rotating forward propagating modes). The resultant circumferential groove noise remains between 2.6 and $6.1 \mathrm{~dB}$ around $2 \mathrm{xBPF}$ and $3 \mathrm{xBPF}$ at low fan speeds.

$$
\Delta P W L_{\text {total }}=\Delta P W L_{\text {grooves }}+\Delta P W L_{\text {treatment }}
$$

Table 2 Summary of acoustic casing treatment noise reduction.

\begin{tabular}{|c|c|c|c|}
\hline & Groove Effect & Treatment Effect & Total Effect \\
\hline In-duct Sound Power Level $(\mathbf{d B})$ & $\Delta P W L_{\text {grooves }}$ & $\Delta P W L_{\text {treatment }}$ & $\Delta P W L_{\text {total }}$ \\
\hline Forward Propagating Modes & $-1.6 \mathrm{~dB}$ & $-1-2 \mathrm{~dB}$ & $-2.6-3.6 \mathrm{~dB}$ \\
\hline Co-rotating Forward Propagating Modes & $-1.7 \mathrm{~dB}$ & $-1.8-2.9 \mathrm{~dB}$ & $-3.5-4.6 \mathrm{~dB}$ \\
\hline Circumferential Groove Noise & $+7.6 \mathrm{~dB}$ & $-1.5-5 \mathrm{~dB}$ & $+2.6-6.1 \mathrm{~dB}$ \\
\hline
\end{tabular}




\section{Conclusion}

NASA has continued development of advanced acoustic liners by completing a series of tests to better understand the effects of over-the-rotor acoustic liners. The final of these tests was a Technology Readiness Level (TRL) 3 test of four acoustic casing treatment concepts and two baseline configurations in the W-8 Single Stage Axial Compressor Facility at NASA GRC. The test utilized the R4 turbofan rotor in a rotor alone configuration. An inlet in-duct array was utilized to extract in-duct sound power levels from the internal flow facility. The array data was processed to decompose the inlet sound field into modal sound powers for the further evaluation of acoustic treatment effects.

Since this was the first time acquiring acoustic data in the W-8 facility, the measurements were validated with Source Diagnostic Test (SDT) Rotor Alone Nacelle (RAN) inlet array data. The in-duct sound pressure levels compared well with a few exceptions; blade passing frequency tones were cut-on in W-8, and the presence of background exhaust noise in the W-8 facility (when the exhaust flow is subsonic).

Acoustic analysis of the fan case configurations tested were used to extract the effect of circumferential grooves from the effect of acoustic treatments placed at the bottoms of circumferential grooves. There was a tip clearance difference between the hardwall and grooved fan cases. The impact of this tip clearance difference was quantified with data from an earlier tip clearance study of the far-field impact of tip clearance on this fan. The circumferential grooves were found to reduce noise over the frequency range from $1-2 \mathrm{kHz}$ by up to $1.7 \mathrm{~dB}$ PWL while increasing noise around $2 \mathrm{xBPF}$ and $3 \mathrm{xBPF}$ by up to $7.6 \mathrm{~dB}$ PWL at low fan speeds. At higher fan speeds, the circumferential grooves had very little impact. The acoustic treatments incorporated at the bottoms of the circumferential grooves provided an additional 1 to $2 \mathrm{~dB}$ PWL (or 2-3dB PWL reduction in co-rotating modes) from $500 \mathrm{~Hz}$ to $1500 \mathrm{~Hz}$. The treatments reduced the circumferential groove noise by $1.5-5 \mathrm{~dB}$ depending on the treatment. At supersonic fan speeds, the treatments appear to have delayed the onset MPTs resulting in PWL reduction of $5 \mathrm{~dB}$ around $1 / 2 \mathrm{BPF}$, while increasing the BPF tone level by about $1.5 \mathrm{~dB}$ PWL.

The net benefit of acoustic treatments with circumferential grooves installed over-the-rotor was measured to be about 2.5-3.5dB reduction in forward propagating modes, and a 3.5-4.5dB reduction in co-rotating (rotor alone) modes. In addition to the noise reduction at low frequencies, a noise increase from the circumferential grooves around $2 \mathrm{xBPF}$ and $3 \times B P F$ was reduced by the acoustic treatments but left a $2.5-6 \mathrm{~dB}$ penalty between $4-8 \mathrm{kHz}$.

The results from this test show the potential for significant turbofan noise reduction from the inclusion of over-therotor acoustic casing treatments. The understanding gained from this series of testing culminating in the TRL 3 test on a high bypass turbofan rotor gives confidence in our ability to adjust treatment designs to target frequencies that maximize effective perceived noise level (EPNL) benefit on a specific application. However, more investigation is required to understand the additional high frequency noise caused by the circumferential grooves.

\section{Acknowledgments}

This work was supported by the Advanced Air Transport Technology Project of NASA's Fundamental Aeronautics Program. The author would like to thank Jim Buckley (Vantage Partners, LLC), and John Jones (ZIN Technologies Inc.) for leading the design and fabrication of hardware and instrumentation for this test. The author would also like the thank the W-8 Single Stage Axial Compressor Facility staff for their work re-validating the facility and executing this test. 


\section{References}

[1] Sutliff, D. L., Jones, M. G., and Hartley, T. C., "High-Speed Turbofan Noise Reduction Using Foam-Metal Liner Over-the-Rotor," Journal of Aircraft, Vol. 50, No. 5, 2013, pp. 1491-1503. doi:10.2514/1.c032021, URL https://doi.org/10.2514/1. CQ32021

[2] Hughes, C., and Gazzaniga, J., "Effect of Two Advanced Noise Reduction Technologies on the Aerodynamic Performance of an Ultra High Bypass Ratio Fan," No. AIAA-2009-3139 in Aeroacoustics Conferences, American Institute of Aeronautics and Astronautics, 2009. doi:10.2514/6.2009-3139, URL https://doi .org/10.2514/6.2009-3139

[3] Bozak, R., Hughes, C., and Buckley, J., "The Aerodynamic Performance of an Over-the-Rotor Liner With Circumferential Grooves on a High Bypass Ratio Turbofan Rotor," GT2013-95114, 2013. doi:10.1115/gt2013-95114, URL http://dx . doi. org/10.1115/GT2013-95114

[4] Gazella, M., Takakura, T., Sutliff, D. L., Bozak, R., and Tester, B. J., "Evaluating the Acoustic Benefits of Over-the-Rotor Acoustic Treatments Installed on the Advanced Noise Control Fan," No. AIAA-2017-3872 in AIAA AVIATION Forum, American Institute of Aeronautics and Astronautics, 2017. doi:10.2514/6.2017-3872, URL https://doi . org/10.2514/6.2017-3872

[5] Van Zante, D. E., Podboy, G. G., Miller, C. J., and Thorp, S. A., “Testing and Performance Verification of a High Bypass Ratio Turbofan Rotor in an Internal Flow Component Test Facility," GT2013-95114, 2007. doi:10.1115/gt2007-27246, URL http://dx.doi.org/10.1115/GT2007-27246.

[6] Elliott, D., Woodward, R., and Podboy, G., "Acoustic Performance of Novel Fan Noise Reduction Technologies for a High Bypass Model Turbofan at Simulated Flight Conditions," 15th AIAA/CEAS Aeroacoustics Conference (30th AIAA Aeroacoustics Conference), No. AIAA-2009-3140 in Aeroacoustics Conferences, American Institute of Aeronautics and Astronautics, 2009. doi:10.2514/6.2009-3140, URL https://doi.org/10.2514/6.2009-3140

[7] Hughes, C., Woodward, R., and Podboy, G., "Effect of Tip Clearance on Fan Noise and Aerodynamic Performance," No. AIAA2005-2875 in Aeroacoustics Conferences, American Institute of Aeronautics and Astronautics, 2005. doi:10.2514/6.2005-2875, URL https://doi.org/10.2514/6.2005-2875.

[8] Hughes, C., Jeracki, R., Woodward, R., and Miller, C., "Fan Noise Source Diagnostic Test - Rotor Alone Aerodynamic Performance Results," No. AIAA-2002-2426 in Aeroacoustics Conferences, American Institute of Aeronautics and Astronautics, 2002. doi:10.2514/6.2002-2426, URL https://doi.org/10.2514/6.2002-2426

[9] Woodward, R., Hughes, C., Jeracki, R., and Miller, C., "Fan Noise Source Diagnostic Test - Far-field Acoustic Results," Aeroacoustics Conferences, American Institute of Aeronautics and Astronautics, 2002. doi:10.2514/6.2002-2427, URL https://doi.org/10.2514/6.2002-2427

[10] Bozak, R. F., "Inlet Acoustic Data from a High Bypass Ratio Turbofan Rotor in an Internal Flow Component Test Facility,” NASA TM-2017-219489, 2017. URL https://ntrs.nasa.gov/archive/nasa/casi.ntrs.nasa.gov/20170004843.pdf

[11] Dougherty, R. P., and Bozak, R. F., “Two-dimensional Modal Beamforming in Wavenumber Space for Duct Acoustics,” To be published in 2018 AIAA Aviation, American Institute of Aeronautics and Astronautics, 2018.

[12] Morfey, C., "SOUND TRANSMISSION AND GENERATION IN DUCTS WITH FLOW," Journal of Sound and Vibration, Vol. 14, No. 1, 1971, pp. 37-55. doi:10.1016/0022-460X(71)90506-2, URL https://doi .org/10.1016/0022-460X(71) $90506-2$

[13] Premo, J., and Joppa, P., "Fan Noise Source Diagnostic Test - Wall Measured Circumferential Array Mode Results," No. AIAA2002-2429 in Aeroacoustics Conferences, American Institute of Aeronautics and Astronautics, 2002. doi:10.2514/6.2002-2429, URL https://doi.org/10.2514/6.2002-2429.

[14] "Tip load modulation as a source of discrete tone fan noise," INTER-NOISE and NOISE-CON Congress and Conference Proceedings, Vol. 1973, No. 2, 1973.

[15] Gliebe, P. R., and Kerschen, E. J., "Analytical study of the effects of wind tunnel turbulence on turbofan rotor noise." NASA-CR-152359, NASA Contractor Report, 1979. URL https://ntrs.nasa.gov/archive/nasa/casi.ntrs.nasa. gov/19800014610.pdf.

[16] Joppa, P. D., "Acoustic mode measurements in the inlet of a turbofan engine," Journal of Aircraft, Vol. 24, No. 9, 1987, pp. 587-593. doi:10.2514/3.45482, URL https://doi.org/10.2514/3.45482

[17] Dougherty, R. P., “Cross-Spectral Matrix Diagonal Optimization,” BeBeC-2016-S2, Berlin Beamforming Conference, 2016. URL http://www . bebec.eu/Downloads/BeBeC2016/Papers/BeBeC-2016-S2.pdf. 